\title{
Tunable spin-state bistability in a spin crossover molecular complex
}

\author{
Xuanyuan Jiang ${ }^{1} \oplus$, Guanhua $\mathrm{Hao}^{1}{ }^{\oplus},{\text { Xiao } \text { Wang }^{2} \odot \text {, Aaron Mosey }}^{3} \oplus$, \\ Xin Zhang ${ }^{4}$, Le $\mathrm{Yu}^{2}$, Andrew J Yost ${ }^{1}{ }^{1}$, Xin Zhang ${ }^{1}$, Anthony D DiChiara ${ }^{5}$,

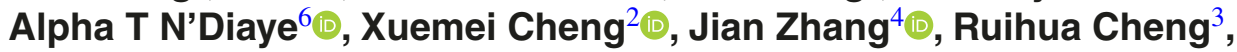 \\ Xiaoshan $X_{\mathbf{u}^{1,7}}$ and Peter A Dowben ${ }^{1,7}$ \\ 1 Department of Physics and Astronomy, University of Nebraska, Lincoln, NE 68588, \\ United States of America \\ 2 Department of Physics, Bryn Mawr College, Bryn Mawr, PA 19010, United States of America \\ 3 Department of Physics, Indiana University Purdue University-Indianapolis, Indianapolis IN 46202, \\ United States of America \\ ${ }^{4}$ Department of Chemistry, University of Nebraska, Lincoln, NE 68588, United States of America \\ 5 Advanced Photon Source, Argonne National Laboratory, Argonne, IL 60439, United States of America \\ ${ }^{6}$ Lawrence Berkeley National Laboratory, Berkeley, CA 94720-8229, United States of America \\ 7 Nebraska Center for Materials and Nanoscience, University of Nebraska, Lincoln, NE 68588, \\ United States of America \\ E-mail: pdowben@unl.edu
}

Received 22 March 2019, revised 10 April 2019

Accepted for publication 17 April 2019

Published 22 May 2019

\begin{abstract}
The spin crossover ( $\mathrm{SCO}$ ) transitions at both the surface and over the entire volume of the $\left[\mathrm{Fe}\left\{\mathrm{H}_{2} \mathrm{~B}(\mathrm{pz})_{2}\right\}_{2}\right.$ (bipy)] polycrystalline films on $\mathrm{Al}_{2} \mathrm{O}_{3}$ substrates have been studied, where $\mathrm{pz}=$ pyrazol-1-yl and bipy $=2,2^{\prime}$-bipyridine. For $\left[\mathrm{Fe}\left\{\mathrm{H}_{2} \mathrm{~B}(\mathrm{pz})_{2}\right\}_{2}\right.$ (bipy)] films of hundreds of $\mathrm{nm}$ thick, magnetometry and $\mathrm{x}$-ray absorption spectroscopy measurements show thermal hysteresis in the SCO transition with temperature, although the transition in bulk $\left[\mathrm{Fe}\left\{\mathrm{H}_{2} \mathrm{~B}(\mathrm{pz})_{2}\right\}_{2}\right.$ (bipy)] occurs in a non-hysteretic fashion at $157 \mathrm{~K}$. While the size of the crystallites in those films are similar, the hysteresis becomes more prominent in thinner films, indicating a significant effect of the $\left[\mathrm{Fe}\left\{\mathrm{H}_{2} \mathrm{~B}(\mathrm{pz})_{2}\right\}_{2}\right.$ (bipy) $] / \mathrm{Al}_{2} \mathrm{O}_{3}$ interface. Bistability of spin states, which can be inferred from the thermal hysteresis, was directly observed using temperature-dependent x-ray diffraction; the crystallites behave as spin-state domains that coexist during the transition. The difference between the spin state of molecules at the surface of the $\left[\mathrm{Fe}\left\{\mathrm{H}_{2} \mathrm{~B}(\mathrm{pz})_{2}\right\}_{2}\right.$ (bipy)] films and that of the molecules within the films, during the thermal cycle, indicates that both cooperative (intermolecular) effects and coordination are implicated in perturbations to the SCO transition.
\end{abstract}

Keywords: spin crossover molecule, bistability, cooperative effects, interfaces

(Some figures may appear in colour only in the online journal)

\section{Introduction}

In spin crossover (SCO) molecular materials, transition metal centers exhibit spin-state transitions that are driven by entropy and structural changes [1-5]. These SCO transitions, although molecular in origin [3], become cooperative when the molecules are coupled in a solid, yielding phase-transition-like changes of spin states and even hysteresis in the SCO transition in thermal cycles (as schematically indicated in figure 1(a)), due to the intrinsic coupling of spin state and structure [2]. Various external stimuli can trigger SCO transitions by perturbing either the structure (pressure $[2,5,6]$ ) or the electronic states (light [7-13], charge injection and electromagnetic field [14-16]). This sensitivity to external stimuli may be exploited to realize molecular switches for next generation information storage and processing applications [14, 15, 17-28]. 


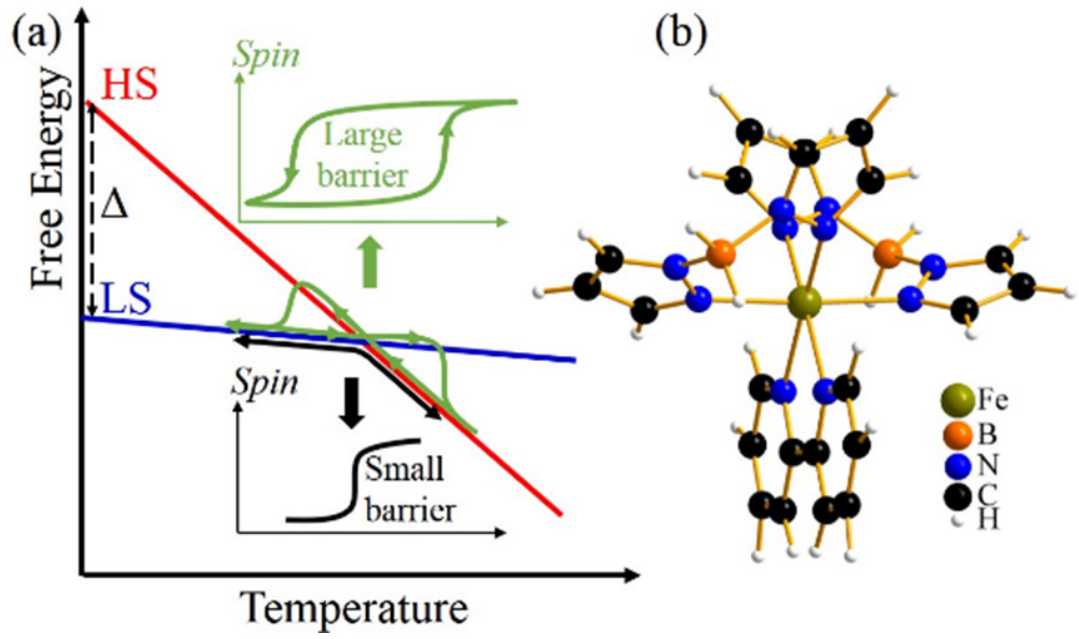

Figure 1. (a) Schematic energy diagram of the SCO transition, in which the free energy changes with temperature according to entropy. HS state (HS) $\leftrightarrow$ LS state transition temperature depends on the enthalpy difference $\Delta$ between the spin states. The width of the hysteresis depends on the free-energy barrier between spin states. (b) Molecular structure of $\left[\mathrm{Fe}\left\{\mathrm{H}_{2} \mathrm{~B}(\mathrm{pz})_{2}\right\}_{2}(\right.$ bipy) $]$.

For widespread applications, one key aspect of the molecular switches is the non-volatile control, which for SCO molecular complexes, requires bistability of the spin states, ideally over a broad temperature range, around room temperature $[11,29,30]$. Naturally, the coupling of spin state and structure may be employed to achieve this bistability [2]. The challenge is to find the proper enthalpy differences between the spin states (denoted as $\Delta$ in figure $1($ a)) to place the SCO transition around room temperature and suitable structural differences between the spin states to generate sizable hysteresis [2, 3, 5, 29]. Another route to achieving these goals is to make use of perturbation caused by interactions at a substrate-film interface, because (1) the electronic and structural couplings at the interface may change the enthalpy difference of the spin states $(\Delta)$ which changes the SCO transition temperatures; (2) the modification of the energy barrier between the spin states, by the interface, can tune the width of the hysteresis loop [28, 30-34]. In this regard, the spin state of thin-film $\left[\mathrm{Fe}\left\{\mathrm{H}_{2} \mathrm{~B}(\mathrm{pz})_{2}\right\}_{2}\right.$ (bipy)], a $\mathrm{Fe}$ (II) molecular SCO complex, exhibits remarkable tunability, where $\mathrm{H}_{2} \mathrm{~B}(\mathrm{pz})_{2}=$ bis(hydrido)bis(1H-pyrazol-1-yl)borate, bipy $=2,2^{\prime}$-bipyridine, as shown in figure 1(b). It has already been established that oxide substrates like $\mathrm{SiO}_{2}$ [34], $\mathrm{Al}_{2} \mathrm{O}_{3}$ [34], $\mathrm{NiCO}_{2} \mathrm{O}_{4}$ [16], and $\mathrm{La}_{0.67} \mathrm{Sr}_{0.33} \mathrm{MnO}_{3}(001)$ [16] tends to lock very thin $\left[\mathrm{Fe}\left\{\mathrm{H}_{2} \mathrm{~B}(\mathrm{pz})_{2}\right\}_{2}\right.$ (bipy)] molecular films $(<40 \mathrm{~nm})$ in a largely low-spin (LS) state, to temperatures well above the thermal SCO transition temperature, where the high-spin (HS) state would be generally favored. A comparison of different measurements of the spin-state occupancy suggests that a significant shift of the transition temperature is indeed possible [35]. On the other hand, the effect of the interface on the spin-state bistability, which is caused by the energy barrier between the spin states, has not been fully investigated.

Here we focus on the molecular complex $\left[\mathrm{Fe}\left\{\mathrm{H}_{2} \mathrm{~B}(\mathrm{pz})_{2}\right\}_{2}\right.$ (bipy)] [36, 37], which is among the few SCO molecules that can be evaporated in vacuum without decomposition [9, 16, 28, 34-40]. This molecule exhibits a non-hysteretic transition between a high-temperature HS state and a low-temperature LS state at $T_{1 / 2}=157 \mathrm{~K}$ in bulk [28, 35-39]. A thermal activation energy of about $60 \pm 7 \mathrm{meV}$ was ascertained for $\left[\mathrm{Fe}\left\{\mathrm{H}_{2} \mathrm{~B}(\mathrm{pz})_{2}\right\}_{2}\right.$ (bipy)] thin films on $\mathrm{SiO}_{2}$ [34], consistent with the measured enthalpy of about $80 \mathrm{meV}$ [39]. The HS and the LS states of the Fe(II) complex correspond to electronic configurations of $t_{2 \mathrm{~g}}^{4} e_{\mathrm{g}}^{2}(S=2)$ and $t_{2 \mathrm{~g}}^{6} e_{\mathrm{g}}^{0}(S=0)$ respectively, where $e_{\mathrm{g}}$ and $t_{2 \mathrm{~g}}$ are the $\mathrm{Fe} 3 d$ states split due to the ligand field. We found that the $\left[\mathrm{Fe}\left\{\mathrm{H}_{2} \mathrm{~B}(\mathrm{pz})_{2}\right\}_{2}\right.$ (bipy)] films, hundreds of $\mathrm{nm}(300 \mathrm{~nm}, 900 \mathrm{~nm})$ thick, surprisingly exhibit spin-state hysteresis in thermal cycles around the bulk SCO transition temperature, which suggests bistability.

\section{Experimental}

The $300 \mathrm{~nm}$ and $900 \mathrm{~nm}$ polycrystalline $\left[\mathrm{Fe}\left\{\mathrm{H}_{2} \mathrm{~B}(\mathrm{pz})_{2}\right\}_{2}\right.$ (bipy)] films were deposited on $5 \times 5 \mathrm{~mm}^{2} \quad \mathrm{Al}_{2} \mathrm{O}_{3}$ substrates (at $300 \mathrm{~K})$ using physical vapor deposition in high vacuum $\left(1.0 \times 10^{-7}\right.$ Torr $)$, with a growth rate of $0.1 \AA \mathrm{s}^{-1}$. The film morphology and thickness calibration was measured by atomic force microscopy and the RMS (root mean square roughness) was found to be about $50 \mathrm{~nm}$. The temperature dependent (cooling, $2 \mathrm{~K} \mathrm{~min}^{-1}$ ) x-ray $(500 \mathrm{~Hz}, 80 \mathrm{ps}$ pulse, $1.033 \AA$ ) diffraction was carried out at the beamline 14ID-B in the Advanced Photon Source at the Argonne National Lab. The X-ray powder diffraction patterns were measured using a 2D Rayonix MX340-HS detector $40 \mathrm{~cm}$ away from the sample and perpendicular to the incident $\mathrm{x}$-ray on a $20 \times 20$ $\mu \mathrm{m}^{2}$ sample spot for a period of $5 \mathrm{~min}$ for every temperature. The $\mathrm{x}$-ray damage on $\left[\mathrm{Fe}\left\{\mathrm{H}_{2} \mathrm{~B}(\mathrm{pz})_{2}\right\}_{2}\right.$ (bipy)] films was checked before the temperature-dependent x-ray diffraction, which showed neither structure change nor material loss after $1.0 \times 10^{5} \mathrm{x}$-ray shots. The sample temperature was controlled using a Cryostream system and calibrated using the lattice constants of the substrates obtained from the experimental diffraction angles.

Temperature dependence of the $\left[\mathrm{Fe}\left\{\mathrm{H}_{2} \mathrm{~B}(\mathrm{pz})_{2}\right\}_{2}\right.$ (bipy)] magnetic susceptibility (an indicator of spin state) was measured using superconducting quantum interference device 
(SQUID) magnetometer. The soft x-ray absorption spectroscopy (XAS) measurements were performed at the bending magnet beamline 6.3.1, at the Advanced Light Source at Lawrence Berkeley National Laboratory, as in other studies of $\left[\mathrm{Fe}\left\{\mathrm{H}_{2} \mathrm{~B}(\mathrm{pz})_{2}\right\}_{2}\right.$ (bipy)] thin films on $\mathrm{Al}_{2} \mathrm{O}_{3}$ [34]. The photon flux was estimated to be around $1.65 \times 10^{5}$ photons $/ \mathrm{s} / \mu \mathrm{m}^{2}$. $\mathrm{X}$-ray absorption spectra were obtained, in both the total electron yield (TEY) mode and photoluminescence yield mode (PLY) at the same time, at the absorption of the Fe $\mathrm{L}_{3}$ edge. In the TEY mode, the XAS data was recorded by measuring the compensation current from ground to the sample, proportional to the TEY from the sample. Due to the limited effective electron sampling depth $\lambda_{\mathrm{e}}$, which is only a few $\mathrm{nm}$ or less, XAS acquired in the TEY mode is more sensitive to the surface properties of the $\left[\mathrm{Fe}\left\{\mathrm{H}_{2} \mathrm{~B}(\mathrm{pz})_{2}\right\}_{2}\right.$ (bipy)] thin film than those acquired in the PLY mode, where there is X-ray transmission through the whole film, and photoluminescence in the sample is detected. The combination of the TEY and the PLY modes made it possible to characterize the surface and bulk property simultaneously across a temperature range from $80 \mathrm{~K}$ to $300 \mathrm{~K}$ for both cooling and heating sequences. As noted above, one problem faced in these specific x-ray absorption experiments is that the $\mathrm{x}$-rays initiate a spin state change for $\left[\mathrm{Fe}\left\{\mathrm{H}_{2} \mathrm{~B}(\mathrm{pz})_{2}\right\}_{2}\right.$ (bipy)] on many dielectric substrates, as discussed elsewhere $[16,34,35]$. That means the influence of the X-ray excitation should be kept as low as possible while absorption data must be acquired rapidly, so as to avoid having the measured spin state occupancy to be too strongly affected by the measurement process. Only then the influence of molecular coordination on cooperative effects resulting in hysteresis and shifts in the thermal SCO transition can be resolved. In the case of the thin film studies, reported here, the XAS spectra have degraded energy resolution due to the need for rapid data acquisition so as to acquire spin state transition rates. The typical $\mathrm{Fe}_{3}$-edge spectrum, for the $300 \mathrm{~nm}$ $\left[\mathrm{Fe}\left\{\mathrm{H}_{2} \mathrm{~B}(\mathrm{pz})_{2}\right\}_{2}\right.$ (bipy)] thin films on $\mathrm{Al}_{2} \mathrm{O}_{3}$, was acquired in ca. $15 \mathrm{~s}$, as in previous studies $[16,34]$.

\section{Results and discussion}

\subsection{Effect of the substrate/film interface}

The temperature dependence of magnetic susceptibility for two different $\left[\mathrm{Fe}\left\{\mathrm{H}_{2} \mathrm{~B}(\mathrm{pz})_{2}\right\}_{2}\right.$ (bipy)] films are compared with that of the powder in figure 2. Unlike the powder form, which shows minimum hysteresis as seen in figure 2 and reported elsewhere [36-39], both $\left[\mathrm{Fe}\left\{\mathrm{H}_{2} \mathrm{~B}(\mathrm{pz})_{2}\right\}_{2}\right.$ (bipy)] films thicknesses on $\mathrm{Al}_{2} \mathrm{O}_{3}$ exhibit more prominent hysteresis of the SCO transition. For the $900 \mathrm{~nm}$ thick $\left[\mathrm{Fe}\left\{\mathrm{H}_{2} \mathrm{~B}(\mathrm{pz})_{2}\right\}_{2}\right.$ (bipy)] film, $T_{1 / 2}$ equals to $152 \mathrm{~K}$ in cooling processes and $157 \mathrm{~K}$ in warming processes, respectively. Thus $\Delta T_{1 / 2}=T_{1 / 2}^{\text {warm }}-T_{1 / 2}^{\text {cool }}=5 \mathrm{~K}$. The temperature dependence of the magnetic susceptibility (or spin-state occupancy) of $300 \mathrm{~nm}$ film deviates more significantly from the bulk behavior. As shown in figure 2(c), the hysteresis measured using magnetometry shows $\Delta T_{1 / 2}=T_{1 / 2}^{\text {warm }}-T_{1 / 2}^{\text {cool }}=15 \mathrm{~K}$ in the $300 \mathrm{~nm}$ film, which is three times compared to $\Delta T_{1 / 2}$ in $900 \mathrm{~nm}$ film. The differences

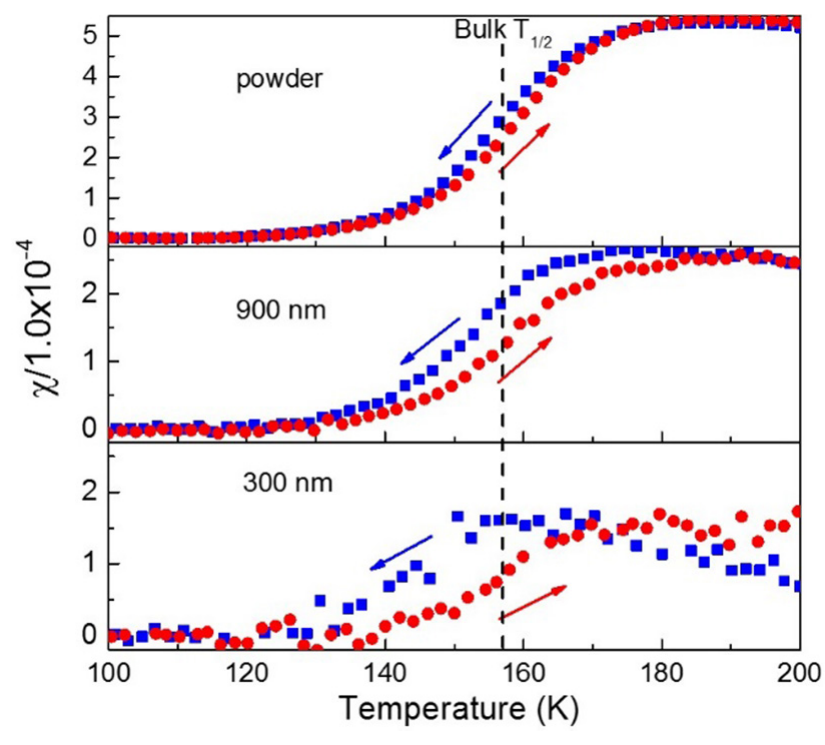

Figure 2. Magnetic susceptibility ( $\chi$ ) of (a) powder (b) $900 \mathrm{~nm}$ and (c) $300 \mathrm{~nm}\left[\mathrm{Fe}\left\{\mathrm{H}_{2} \mathrm{~B}(\mathrm{pz})_{2}\right\}_{2}\right.$ (bipy)] films, on $\mathrm{Al}_{2} \mathrm{O}_{3}$, in thermal cycles plotted as scatters dots.

in the extent of the hysteresis, $\Delta T_{1 / 2}$, suggest that the average energy barrier between the HS and LS states is larger in the $300 \mathrm{~nm}$ films than that in the $900 \mathrm{~nm}$ films.

To further probe the transition between the spin states in the $300 \mathrm{~nm}$ films, we carried out temperaturedependent $\mathrm{x}$-ray diffraction measurements. The structures of $\left[\mathrm{Fe}\left\{\mathrm{H}_{2} \mathrm{~B}(\mathrm{pz})_{2}\right\}_{2}\right.$ (bipy)] in bulk are monoclinic with space group $\mathrm{C} 2 / \mathrm{c}$ for both the HS and the LS states [37]. On the other hand, previous work shows that the lattice constants of the HS state (at $300 \mathrm{~K}$ ) and that of the LS state (at $140 \mathrm{~K}$ ) differ by about $1.5 \%$ which is much larger than what is expected from thermal expansion [37]. This significant difference in lattice constants can be employed to probe the spin state occupancies using $\mathrm{X}$-ray diffraction.

Figure 3(a) shows a typical 2D x-ray powder diffraction pattern. Integrating the azimuthal angle, one gets the powder diffraction intensity as a function of $2 \theta$ (diffraction spectrum), which is consistent with the $\mathrm{C} 2 / \mathrm{c}$ structure. Figure 3(b) shows

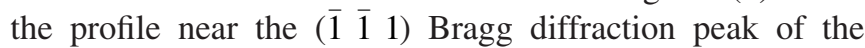
$300 \mathrm{~nm}$ thick $\left[\mathrm{Fe}\left\{\mathrm{H}_{2} \mathrm{~B}(\mathrm{pz})_{2}\right\}_{2}\right.$ (bipy)] film at 125 and $255 \mathrm{~K}$. The diffraction profile at $125 \mathrm{~K}$ clearly has a main peak and a shoulder of a similar width at larger $2 \theta$, so the diffraction profile can be fit using two Gaussian functions, as shown by the dashed lines. The centers of the main peak and the shoulder in figure 3(b) differ by about $1.4 \%$, suggesting that the main peak corresponds to the HS state and the shoulder corresponds to the LS state $[3,37]$.

Figure 3(c) shows the evolution of the ( $\left.\begin{array}{lll}\overline{1} & \overline{1} & 1\end{array}\right)$ diffraction profile when the $300 \mathrm{~nm}$ film sample is cooled; the asymmetric broadening of the peaks at low temperature comes from the enhancement of the LS state. By fitting the diffraction profile with two components, we found that the main diffraction peak shifts towards a higher-angle when the temperature is lowered, as indicated by the line in figure 3(c), consistent with the lattice constant in linear contraction behavior with a coefficient $1.3 \times 10^{-6} \mathrm{~K}^{-1}$. The ratio between the intensity (area) of 

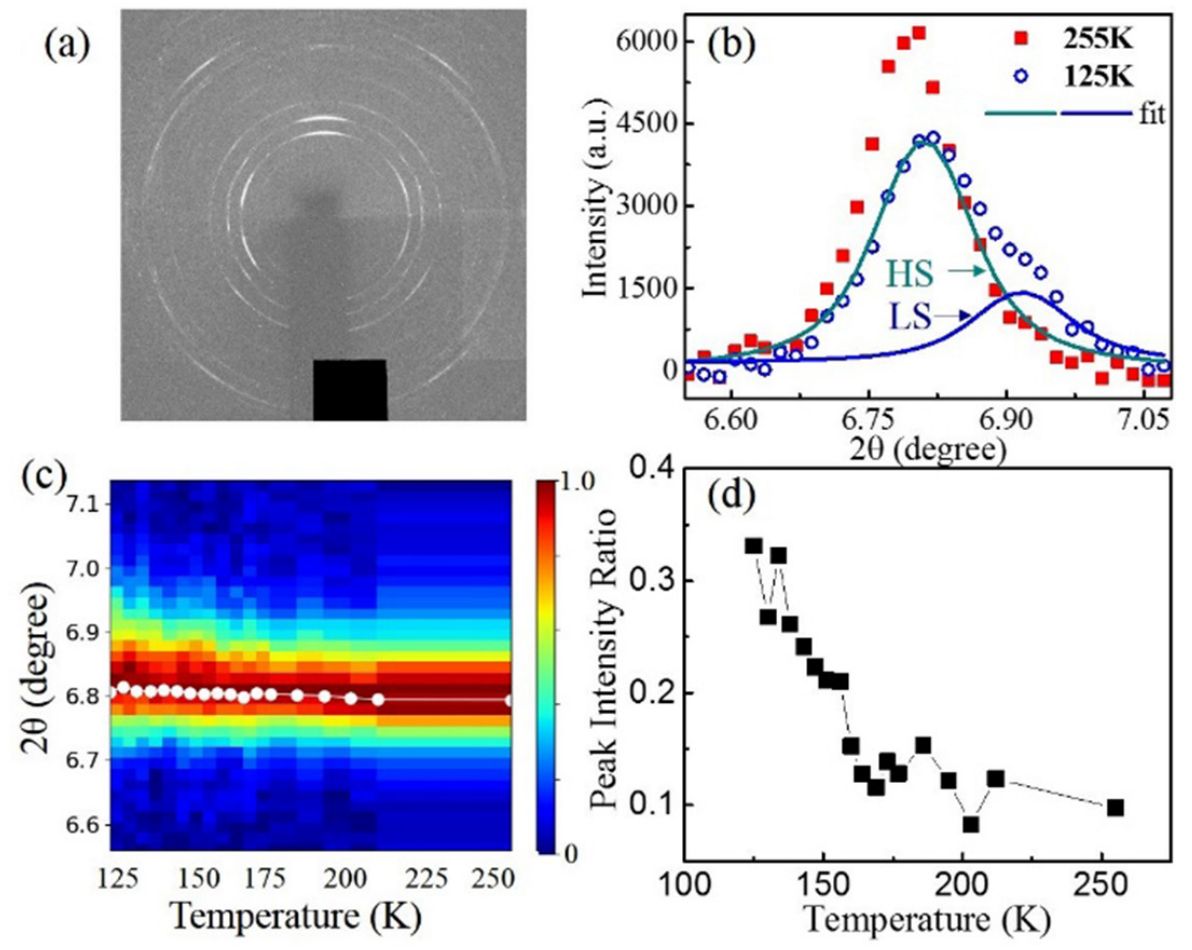

Figure 3. (a) Typical powder x-ray diffraction pattern of $\left[\mathrm{Fe}\left\{\mathrm{H}_{2} \mathrm{~B}(\mathrm{pz})_{2}\right\}_{2}\right.$ (bipy)] films, on $\mathrm{Al}_{2} \mathrm{O}_{3}$, measured using a $2 \mathrm{D}$ detector. The rings show polycrystalline nature of the films. (b)-(d) includes data of a $300 \mathrm{~nm}$ film. (b) Diffraction profiles near the ( $\overline{1} \overline{1} 1)$ Bragg peak; the $125 \mathrm{~K}$ profile is fit using a main peak (HS) and a shoulder peak (LS). (c) Diffraction profiles plotted as a 2D image around the ( $\overline{1} \overline{1} 1)$ Bragg peaks. (d) The intensity ratio between the shoulder (LS) and the main peak (HS) as a function of temperature.
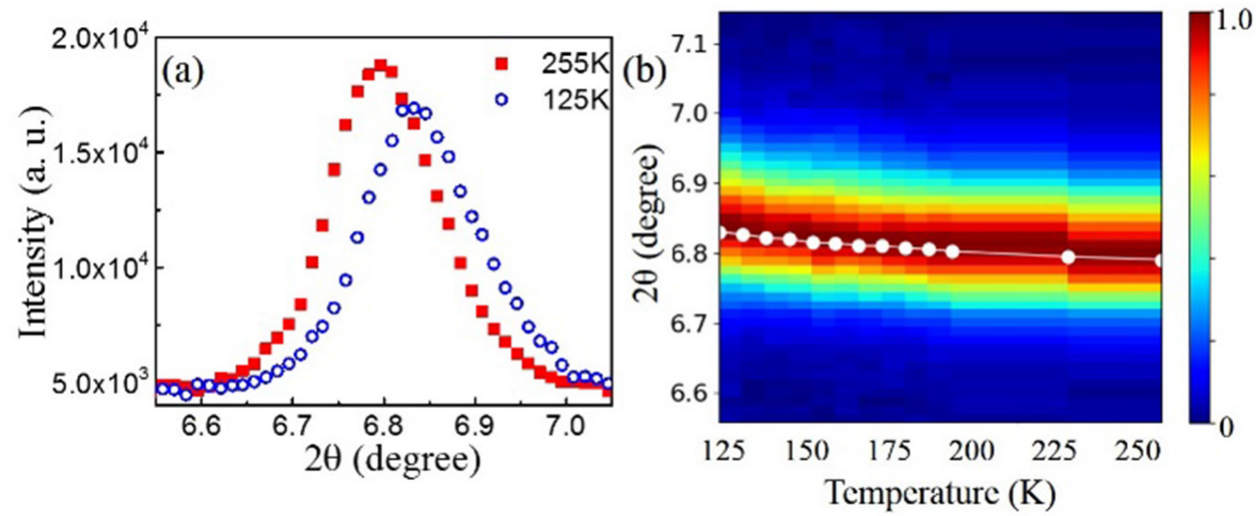

Figure 4. X-ray diffraction of a $900 \mathrm{~nm}$ thick $\left[\mathrm{Fe}\left\{\mathrm{H}_{2} \mathrm{~B}(\mathrm{pz})_{2}\right\}_{2}\right.$ (bipy)] film, on $\mathrm{Al}_{2} \mathrm{O}_{3}$. (a) Diffraction profiles near the ( $(\overline{1} \overline{1} 1) \mathrm{Bragg}$ peak at $125 \mathrm{~K}$ and $255 \mathrm{~K}$. (b) Diffraction profiles plotted as a $2 \mathrm{D}$ image around the ( $(\overline{1} \overline{1} 1)$ Bragg peaks.

the shoulder peak (LS) and that of the main peak (HS) grows upon cooling, as shown in figure 3(d).

Hence, in the $300 \mathrm{~nm}$ film, coexistence of spin state occupancy which indicates bistability, was directly observed using x-ray diffraction, in line with the hysteretic behavior in the magnetic susceptibility (figure 2(b)). Furthermore, the bistability of spin states in the $300 \mathrm{~nm}$ film appears to occur at the crystallite level. As shown in figure 3(b), the widths of the main peak (HS) and the shoulder peak (LS) are similar and insensitive to temperature, indicating that the size of the crystallites for both spin states are similar (about $100 \mathrm{~nm}$ ) [41]. Therefore, the crystallites, as the unit of diffraction, are in either HS or LS state. They are spin-state domains.
In contrast, the coexistence of both HS and LS spin states was less obvious in the x-ray diffraction of $900 \mathrm{~nm}$ films. Figure 4(a) shows the diffraction spectra near the ( $\left(\begin{array}{lll}\overline{1} & \overline{1} & 1\end{array}\right)$ Bragg peaks of the $900 \mathrm{~nm}$ film, in which the size of the crystallites is also about $100 \mathrm{~nm}$ according to the peak width [41]. The shape of the $125 \mathrm{~K}$ spectrum resembles that taken at $255 \mathrm{~K}$. As shown in figure $4(\mathrm{~b})$, the evolution of the ( $\left.\begin{array}{lll}\overline{1} & 1 & 1\end{array}\right)$ diffraction profile, as observed during cooling, behaves more like a peak shift due to a lattice constant change, instead of the appearance of an additional peak. Yet the effects seen are non-linear, with the shift of ( $\left.\begin{array}{lll}\overline{1} & \overline{1} & 1\end{array}\right)$ diffraction profile, toward the higher-angles, occurring faster at lower temperatures. 

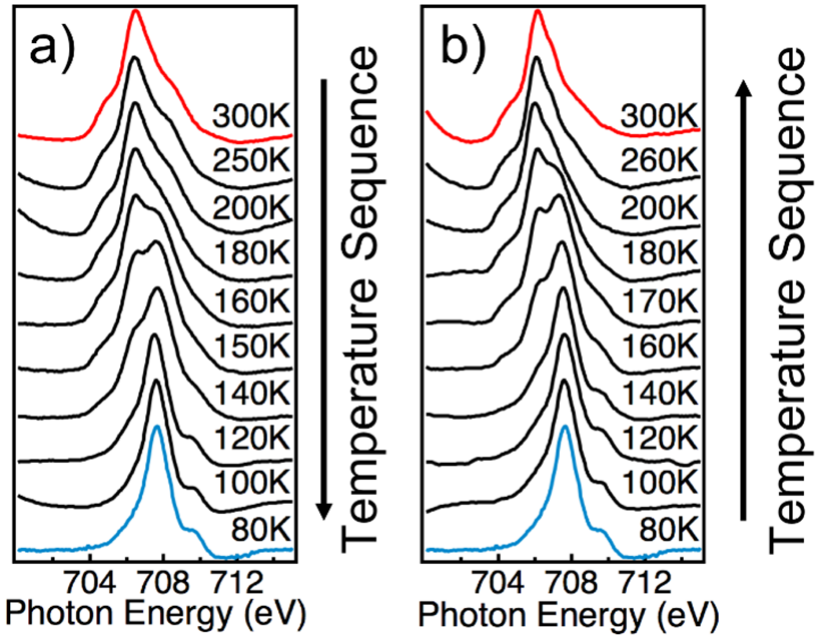

Figure 5. The $\mathrm{x}$-ray absorption spectra, taken in the PLY mode for (a) cooling sequence and (b) heating of $300 \mathrm{~nm}$ $\left[\mathrm{Fe}\left\{\mathrm{H}_{2} \mathrm{~B}(\mathrm{pz})_{2}\right\}_{2}\right.$ (bipy)] thin film on $\mathrm{Al}_{2} \mathrm{O}_{3}$. Red indicates XAS spectra representative of the HS state and blue indicates LS state.

The thickness dependence of the SCO transition in the $\left[\mathrm{Fe}\left\{\mathrm{H}_{2} \mathrm{~B}(\mathrm{pz})_{2}\right\}_{2}\right.$ (bipy)] films on $\mathrm{Al}_{2} \mathrm{O}_{3}$, suggests that different parts of the films behave differently. If the films are divided into three parts: near substrate, interior, and near surface, the near-substrate part most likely contributes to the hysteretic behavior of the SCO transition the most, because it is known that the modification of the energy barrier between the spin states of the molecules by the interface can tune the width of the hysteresis loop [28, 30-33]. For the $\left[\mathrm{Fe}\left\{\mathrm{H}_{2} \mathrm{~B}(\mathrm{pz})_{2}\right\}_{2}\right.$ (bipy)]/ $\mathrm{Al}_{2} \mathrm{O}_{3}$ interface, in particular, the LS state of very thin films $(<40 \mathrm{~nm})$ can be locked to temperatures well above the bulk SCO transition temperature, indicating a significant interaction at the substrate/film interface.

\subsection{The effect of the coordination}

The question then is whether the thermal SCO transition is the same at the surface as within the volume of a molecular thin film, of sufficient thickness so that substrate effects are diminished, yet still present. The surface would be of lower coordination and farther away from the interface with the substrate than the interior of the film, thus could be affected differently by the incident $\mathrm{x}$-ray, intermolecular cooperative effects, and the substrate. The spin state occupancy of the $\left[\mathrm{Fe}\left\{\mathrm{H}_{2} \mathrm{~B}(\mathrm{pz})_{2}\right\}_{2}\right.$ (bipy)] $\mathrm{Fe}$ (II) complex may be extracted from the X-ray absorption spectra $[9,16,34,35,40,42]$. In the LS of the $\left[\mathrm{Fe}\left\{\mathrm{H}_{2} \mathrm{~B}(\mathrm{pz})_{2}\right\}_{2}\right.$ (bipy) $]$ molecule, the $3 d$ electrons occupy the $t_{2 \mathrm{~g}}$ orbitals in pairs leaving the $e_{\mathrm{g}}$ orbitals empty. This is generally observed in the $\mathrm{Fe}_{3}$ edge $\left(2 p_{3 / 2}\right) \mathrm{x}$-ray absorption spectra as a major feature at a photon energy around $708 \mathrm{eV}$ (figures 5 and 6). By comparison, in the HS configuration, the $e_{\mathrm{g}}$ orbitals are partially populated while the $t_{2 \mathrm{~g}}$ orbitals subsequently get partly depopulated, which corresponds to the XAS spectra with a decrease of the peak intensity at $708 \mathrm{eV}$ and an increase of the $t_{2 \mathrm{~g}}$ shoulder around $706.5 \mathrm{eV}$. The temperaturedependent XAS of the $\left[\mathrm{Fe}\left\{\mathrm{H}_{2} \mathrm{~B}(\mathrm{pz})_{2}\right\}_{2}\right.$ (bipy)] thin films on $\mathrm{Al}_{2} \mathrm{O}_{3}$, is shown in figures 5 and 6. Figure 5 shows XAS taken
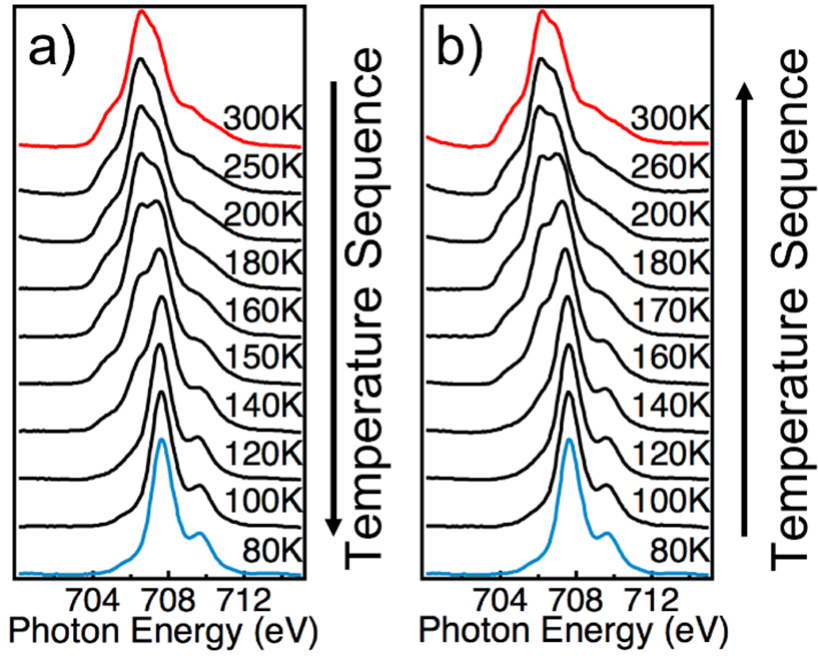

Figure 6. The $\mathrm{x}$-ray absorption spectra, taken in the total electronic yield mode (TEY) for (a) cooling sequence and (b) heating of $300 \mathrm{~nm}\left[\mathrm{Fe}\left\{\mathrm{H}_{2} \mathrm{~B}(\mathrm{pz})_{2}\right\}_{2}\right.$ (bipy)] thin film on $\mathrm{Al}_{2} \mathrm{O}_{3}$. Red indicates XAS spectra representative of the HS state and blue indicates LS state.

in the PLY mode, probing the bulk of $\left[\mathrm{Fe}\left\{\mathrm{H}_{2} \mathrm{~B}(\mathrm{pz})_{2}\right\}_{2}\right.$ (bipy)] thin films on $\mathrm{Al}_{2} \mathrm{O}_{3}$, while figure 6 illustrates the XAS for the $\left[\mathrm{Fe}\left\{\mathrm{H}_{2} \mathrm{~B}(\mathrm{pz})_{2}\right\}_{2}\right.$ (bipy)] films in the TEY mode, where the latter is more surface sensitive. The spectra taken at low temperature in blue (in figures 5 and 6) are representative of the LS state and the spectra in red (in figures 5 and 6) are representative of the HS state. We note that the SCO transition temperature, taken in the TEY mode is close to the expected SCO transition temperature of $157 \mathrm{~K}$, for [ $\mathrm{Fe}\left\{\mathrm{H}_{2} \mathrm{~B}(\mathrm{pz})_{2}\right\}_{2}$ (bipy)] [34-39, 43], although the observed thermal hysteresis make a precise comparison difficult.

To further investigate the occupancy of the HS state, with changing temperature, we have used the 'empty $t_{2 \mathrm{~g}}$ /empty $e_{\mathrm{g}}$ ' ratio as an empirical approximation of molecules in the HS state at a given temperature $[9,16,34,40,42]$. The HS state occupancy upon heating is different from the HS state occupancy upon cooling, as indicated in figure 7, from the analysis of the XAS spectra taken in both the TEY mode and the PLY modes. The SCO transition temperature $T_{1 / 2}(50 \% \mathrm{HS}$ state occupancy), in the TEY mode, the transition temperature $T_{1 / 2}$ for cooling sequence is around $150 \mathrm{~K}$ on cooling the sample, and around $170 \mathrm{~K}$ (figures 6 and 7) on heating. In the PLY mode, $T_{1 / 2}$ is around $160 \mathrm{~K}$ on cooling and $180 \mathrm{~K}$ for the heating sequence and is in agreement with SQUID magnetometry, as seen in the insert in figure 7. Both SQUID magnetometry and XAS in the PLY mode, give around a $20 \mathrm{~K}$ difference of $T_{1 / 2}$ between the cooling and heating process. Also, both the surface (TEY mode) and bulk (PLY mode) exhibit thermal hysteresis in spite of the much lower coordination at the surface of the $\left[\mathrm{Fe}\left\{\mathrm{H}_{2} \mathrm{~B}(\mathrm{pz})_{2}\right\}_{2}\right.$ (bipy) $]$ film, than should be the case in the bulk of the film. The molecules of $\left[\mathrm{Fe}\left\{\mathrm{H}_{2} \mathrm{~B}(\mathrm{pz})_{2}\right\}_{2}\right.$ (bipy)], at the surface layers have vacuum on one side, while in the bulk of the thin film, the $\left[\mathrm{Fe}\left\{\mathrm{H}_{2} \mathrm{~B}(\mathrm{pz})_{2}\right\}_{2}\right.$ (bipy)] molecules are surrounded by other $\left[\mathrm{Fe}\left\{\mathrm{H}_{2} \mathrm{~B}(\mathrm{pz})_{2}\right\}_{2}\right.$ (bipy) $] \mathrm{Fe}$ (II) complex molecules. So the surface of the film has $\left[\mathrm{Fe}\left\{\mathrm{H}_{2} \mathrm{~B}(\mathrm{pz})_{2}\right\}_{2}\right.$ (bipy)] with lower coordination and possibly diminished strain. 


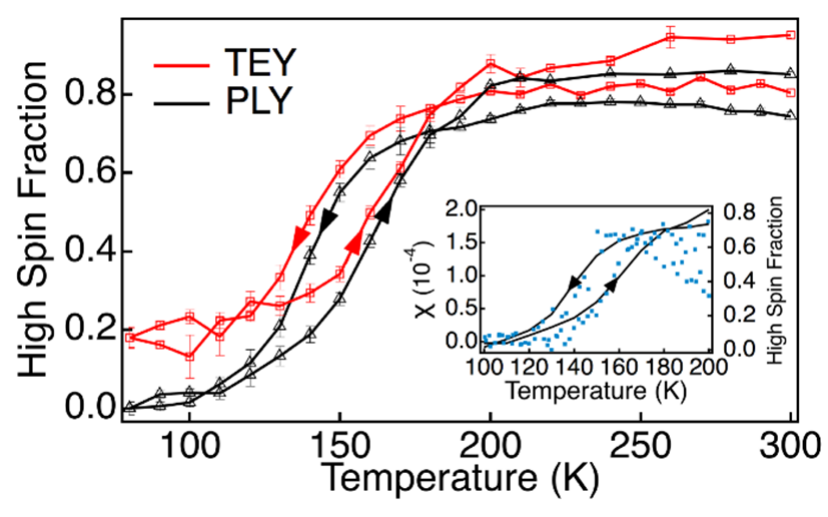

Figure 7. Temperature dependent hysteresis loops for $300 \mathrm{~nm}$ thick $\left[\mathrm{Fe}\left\{\mathrm{H}_{2} \mathrm{~B}(\mathrm{pz})_{2}\right\}_{2}\right.$ (bipy)] thin films on $\mathrm{Al}_{2} \mathrm{O}_{3}$ indicating the HS state occupancy based on XAS taken in TEY mode (red hollow square) and PLY mode (black hollow triangle), arrows indicate cooling sequence and heating sequence. Insert: temperature dependent hysteresis loop measured by SQUID (dots) in comparison to PLY data measured by XAS (lines).

The lower coordination at the surface implies reduced intermolecular interactions, which means that cooperative effects, induced by the $\mathrm{Al}_{2} \mathrm{O}_{3}$ substrate $[16,34]$, that tend to lock the $\left[\mathrm{Fe}\left\{\mathrm{H}_{2} \mathrm{~B}(\mathrm{pz})_{2}\right\}_{2}\right.$ (bipy)] in the LS state, would be diminished at the surface. In this scenario, the influence of the substrate to film interface on $\left[\mathrm{Fe}\left\{\mathrm{H}_{2} \mathrm{~B}(\mathrm{pz})_{2}\right\}_{2}\right.$ (bipy)] would favor the LS state within the bulk of the film, where the coordination is high. This would push the apparent SCO transition temperature, for the bulk of the film, to higher temperatures than the surface, where coordination is low. This is what is observed. As we previously showed, that for the ferroelectric polyvinylidene fluoride (PVDF), the interface interactions favor the HS state in $\left[\mathrm{Fe}\left\{\mathrm{H}_{2} \mathrm{~B}(\mathrm{pz})_{2}\right\}_{2}\right.$ (bipy)] when the ferroelectric is poled towards the $\left[\mathrm{Fe}\left\{\mathrm{H}_{2} \mathrm{~B}(\mathrm{pz})_{2}\right\}_{2}\right.$ (bipy)] molecular film $[44,45]$. This interface with PVDF, unlike $\mathrm{Al}_{2} \mathrm{O}_{3}$, should favor the HS state in the bulk of the film, and the LS state at the surface, where coordination is low. As shown in figure 8, the $\mathrm{X}$-ray absorption spectra, taken in the PLY mode and in the TEY mode for 20 molecular layers of $\left[\mathrm{Fe}\left\{\mathrm{H}_{2} \mathrm{~B}(\mathrm{pz})_{2}\right\}_{2}\right.$ (bipy)] thin film on PVDF, taken at $150 \mathrm{~K}$, indicate the presence of more HS state occupancy in the interior of the film (PLY) than at the surface (TEY). The electronic transition between spin states is enabled by a conformational change of the ligands around the $\mathrm{Fe}$ (II) ion. We suggest, that close to the interface this conformational change is sterically inhibited, whereas closer to the surface changes in conformation can be accommodated or even proliferated by neighboring molecules which are close to the interface. The local charge and strain environment is likely to influence the balance of electrostatic interactions between the ligands making the conformation associated with the LS/HS states favorable close to the interface.

Other explanations cannot be completely excluded. Thermal gradient effects cannot be, a priori, excluded completely on the basis of measurements done here. However, they seem unlikely on the basis of the agreement between the superconducting SQUID magnetometry and the x-ray absorption, taken in the PLY mode. Recent measurements [44] show the electrical resistance is much higher for $\left[\mathrm{Fe}\left\{\mathrm{H}_{2} \mathrm{~B}(\mathrm{pz})_{2}\right\}_{2}\right.$ (bipy)]

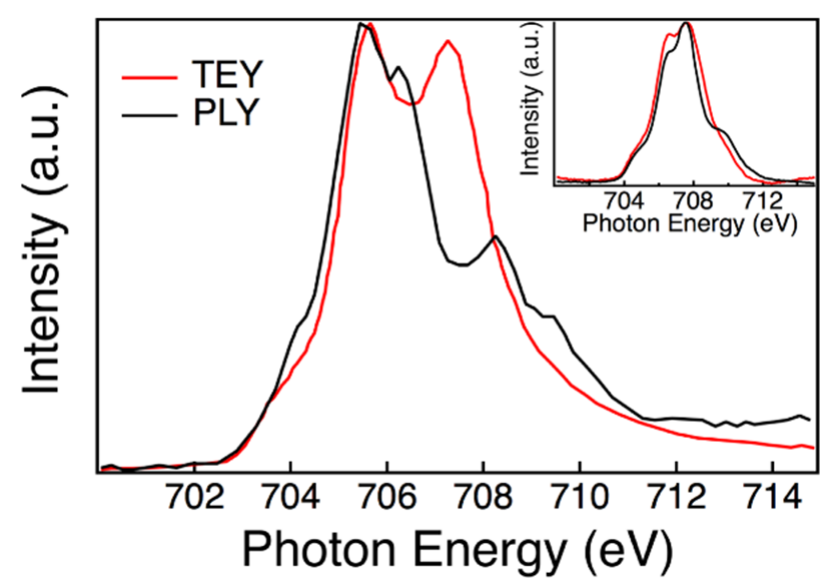

Figure 8. X-ray absorption spectra of $\left[\mathrm{Fe}\left\{\mathrm{H}_{2} \mathrm{~B}(\mathrm{pz})_{2}\right\}_{2}\right.$ (bipy)] thin film on PVDF substrate where the polarization has been poled towards the thin film, taken in the PLY mode (black) and in the TEY mode (red), at temperature $150 \mathrm{~K}$. Insert: $\mathrm{x}$-ray absorption spectra of $\left[\mathrm{Fe}\left\{\mathrm{H}_{2} \mathrm{~B}(\mathrm{pz})_{2}\right\}_{2}\right.$ (bipy)] thin film on $\mathrm{Al}_{2} \mathrm{O}_{3}$ substrate taken in two modes at $150 \mathrm{~K}$.

in the LS state than that in the HS state which might hint at a low thermal conductivity akin to a Wiedemann-Franz law [46]. This potentially permits thermal excitations, associated with the XAS measurement, so that the surface might locally heat more than the bulk due to the lower coordination of $\left[\mathrm{Fe}\left\{\mathrm{H}_{2} \mathrm{~B}(\mathrm{pz})_{2}\right\}_{2}\right.$ (bipy)] species at the surface. If significant, this reduced thermal conductivity could lower the measured SCO transition temperature at the surface compared with the bulk, if significant. Yet such thermal conductivity effects should also serve to decrease the observed thermal hysteresis in the surface SCO transition temperature, which is not seen. Thermal excitations, near the surface, due to the x-ray fluence are unlikely to be the cause - especially given that the $\mathrm{x}$-rays largely pass through the film almost unimpeded. It is hard to see how such thermal effects could be significant on a nanometer scale and remain sufficiently local so as not to perturb the bulk (interior) of the $\left[\mathrm{Fe}\left\{\mathrm{H}_{2} \mathrm{~B}(\mathrm{pz})_{2}\right\}_{2}\right.$ (bipy) $]$ molecular film. This explanation also cannot be reconciled with the results obtained for the $\left[\mathrm{Fe}\left\{\mathrm{H}_{2} \mathrm{~B}(\mathrm{pz})_{2}\right\}_{2}\right.$ (bipy)] thin film on PVDF, shown in figure 8. An alternative explanation, for the observed difference between the surface and the bulk, involves quenching or screening of soft x-ray induced HS excited state configuration. Such quenching or screening of soft x-ray induced HS excited state configuration could indicate cooperative effect or intermolecular interactions, which should be more significant for the higher coordination number at the interface and would be expected to be less significant at the surface. This latter explanation requires a multi-excitation process, one to form the excited state configuration and a second for the core to bound excitation that is the basis for $\mathrm{x}$-ray absorption spectroscopy. These multi-excitations processes, here, would have to occur on much shorter time scale than indicated in prior work [16, 34], i.e. seconds rather than minutes for a large ensemble of $\left[\mathrm{Fe}\left\{\mathrm{H}_{2} \mathrm{~B}(\mathrm{pz})_{2}\right\}_{2}\right.$ (bipy)] species. Again, this explanation also cannot be reconciled with the results obtained for the $\left[\mathrm{Fe}\left\{\mathrm{H}_{2} \mathrm{~B}(\mathrm{pz})_{2}\right\}_{2}\right.$ (bipy)] thin film on PVDF, shown in figure 8. 
The temperature difference between the surface and the bulk spin crossover tranisition temperature, as seen in figure, helps explain the shift in the spin crossover transition temperature seen in magnetometry in figure 2. The $\mathrm{Al}_{2} \mathrm{O}_{3}$ interface likely locks some volume of the $\left[\mathrm{Fe}\left\{\mathrm{H}_{2} \mathrm{~B}(\mathrm{pz})_{2}\right\}_{2}\right.$ (bipy)] thin film in the low spin state [34]. The remaining volume has a higher surface to volume ratio with decreasing film thickness, and thus more influenced by the surface volume, where the spin crossover transition is shifted to lower temperatures.

\section{Conclusions}

In conclusion, the bistability of the spin states and the spin state hysteresis have been observed in the films of hundreds of nanometers in thickness, indicating tunability of the energy barrier between the spin states in $\left[\mathrm{Fe}\left\{\mathrm{H}_{2} \mathrm{~B}(\mathrm{pz})_{2}\right\}_{2}\right.$ (bipy)]. The thickness dependence of the hysteresis and the fact that the size of the crystallites are similar in these films, indicate that this effect comes from the $\left[\mathrm{Fe}\left\{\mathrm{H}_{2} \mathrm{~B}(\mathrm{pz})_{2}\right\}_{2}\right.$ (bipy) $] / \mathrm{Al}_{2} \mathrm{O}_{3}$ interface $[32,47]$. Microscopically, the effect of the interface appears to cause the SCO transition collectively at the crystallite level, which enhances the barrier between the spin states and generates hysteresis and bistability in $\left[\mathrm{Fe}\left\{\mathrm{H}_{2} \mathrm{~B}(\mathrm{pz})_{2}\right\}_{2}\right.$ (bipy)]. The thickness dependence of the hysteresis in spin state also points to a possibility that the temperature range of the bistability can be broadened, perhaps to include room temperature, although this may require a SCO complex different from $\left[\mathrm{Fe}\left\{\mathrm{H}_{2} \mathrm{~B}(\mathrm{pz})_{2}\right\}_{2}\right.$ (bipy)]. We also used the $\mathrm{x}$-ray absorption spectroscopy and magnetometry study to investigate the electronic state of the $\left[\mathrm{Fe}\left\{\mathrm{H}_{2} \mathrm{~B}(\mathrm{pz})_{2}\right\}_{2}\right.$ (bipy)] thin film on $\mathrm{Al}_{2} \mathrm{O}_{3}$ substrates. Cooperative effects have been revealed from the temperature dependent hysteresis loops and confirmed by differences in the SCO transition temperature at the surface and the bulk.

\section{Acknowledgments}

Xuanyuan Jiang and Guanhua Hao contributed equally in this work. This work is primarily supported by the National Science Foundation through the Nebraska Materials Research Science and Engineering Center (Grant No. DMR-1420645) and NSF-Chem 1565692 (G H, A Y, P A D). X M C acknowledges the support from National Science Foundation Grant No. NSF DMR Grants (\#1708790 and \#1053854). This research used resources of the Advanced Photon Source, a US Department of Energy (DOE) Office of Science User Facility operated for the DOE Office of Science by Argonne National Laboratory under Contract No. DE-AC02- 06CH11357. The use of BioCARS was also supported by the National Institute of General Medical Sciences of the National Institutes of Health under Grant No. R24GM111072. The content is solely the responsibility of the authors and does not necessarily represent the official views of the National Institutes of Health. The use of the Advanced Light Source, Lawrence Berkeley National Laboratory, was supported by the US Department of Energy (DOE) under Contract No. DE-AC02-05CH11231.
Research at Nebraska was performed in part in the Nebraska Nanoscale Facility, Nebraska Center for Materials and Nanoscience, which is supported by the NSF under Award NNCI: 1542182, and the Nebraska Research Initiative (NRI).

\section{ORCID iDs}

Xuanyuan Jiang (D) https://orcid.org/0000-0002-2960-0101 Guanhua Hao (1) https://orcid.org/0000-0003-3281-6816 Xiao Wang (i) https://orcid.org/0000-0003-2005-9520 Aaron Mosey (1) https://orcid.org/0000-0003-1513-3968 Andrew J Yost (1) https://orcid.org/0000-0002-6220-7520 Anthony D DiChiara (1) https://orcid.org/0000-0002-2145-3039 Alpha T N'Diaye (i) https://orcid.org/0000-0001-9429-9776 Xuemei Cheng (iD https://orcid.org/0000-0001-6670-4316 Jian Zhang (1) https://orcid.org/0000-0001-9232-427X Xiaoshan Xu (i) https://orcid.org/0000-0002-4363-392X Peter A Dowben (1) https://orcid.org/0000-0002-2198-4710

\section{References}

[1] Gütlich P and Goodwin H A (ed) 2004 Spin Crossover in Transition Metal Compounds I (Berlin: Springer)

[2] Gütlich P, Garcia Y and Goodwin H A 2000 Chem. Soc. Rev. 29419

[3] Halcrow M A 2011 Chem. Soc. Rev. 404119

[4] Gütlich P and Goodwin H A (ed) 2004 Spin Crossover in Transition Metal Compounds II (Berlin: Springer)

[5] Shatruk M, Phan H, Chrisostomo B A and Suleimenova A 2015 Coord. Chem. Rev. 289-90 62-73

[6] Galet A, Gaspar A B, Agusti G, Muñoz M C, Levchenko G and Real J A 2006 Eur. J. Inorg. Chem. 183571

[7] Matsumoto N, Sato T, Hashimoto S, Kojima M and Iijima S 2009 J. Phys.: Conf. Ser. 148012029

[8] Ohkoshi S, Imoto K, Tsunobuchi Y, Takano S and Tokoro H 2011 Nat. Chem. 3564

[9] Warner B et al 2013 J. Phys. Chem. Lett. 41546

[10] Auböck G and Chergui M 2015 Nat. Chem. 7629

[11] Freysz E, Montant S, Létard S and Létard J-F 2004 Chem. Phys. 394318

[12] Bonhommeau S, Molnár G, Galet A, Zwick A, Jeal J-A, McGarvey J J and Bousseksou A 2005 Angew. Chem., Int. Ed. 444069

[13] Cobo S, Ostrovskii D, Bonhommeau S, Vendier L, Molnár G, Salmon L, Tanaka K and Bousseksou A 2008 J. Am. Chem. Soc. 1309019

[14] Miyamachi T et al 2012 Nat. Commun. 3938

[15] Gopakumar T G, Matino F, Naggert H, Bannwarth A, Tuczek F and Berndt R 2012 Angew. Chem., Int. Ed. 516262

[16] Zhang X, N' Diaye A T, Jiang X, Zhang X, Yin Y, Chen X, Hong X, Xu X and Dowben P A 2018 Chem. Commun. 54944

[17] Molnár G, Rat S, Salmon L, Nicolazzi W and Bousseksou A 2018 Adv. Mater. 3017003862

[18] Cornia A and Seneor P 2017 Nat. Mater. 16505

[19] Aravena D and Ruiz E 2012 J. Am. Chem. Soc. 134777

[20] Kuch W and Bernien M J 2017 J. Phys.: Condens. Matter 29023001

[21] Ludwig E, Naggert H, Kalläne M, Rohlf S, Kröger E, Bannwarth A, Quer A, Rossnagel K, Kipp L and Tuczek F 2014 Angew. Chem., Int. Ed. $\mathbf{5 3} 3019$ 
[22] Mahfoud T, Molnar G, Bonhommeau S, Cobo S, Salmon L, Demont P, Tokoro H, Ohkoshi S-I, Boukheddade K and Bousseksou A 2009 J. Am. Chem. Soc. 13115049

[23] Mahfoud T, Molnar G, Cobo S, Salmon L, Thibault C, Vieu C, Demont P and Bousseksou A 2011 Appl. Phys. Lett. 99053307

[24] Prins F, Monrabal-Capilla M, Osorio E A, Coronado E and van der Zant H S 2011 J. Adv. Mater. 231545

[25] Rotaru A, Gural'skiy I Y A, Molnar G, Salmon L, Demont P and Bousseksou A 2012 Chem. Commun. 484163

[26] Rotaru A, Dugay J, Tan R P, Gural'skiy I A, Salmon L, Demont P, Carrey J, Molnar G, Respaud M and Bousseksou A 2013 Adv. Mater. 251745

[27] Ruiz E 2014 Phys. Chem. Chem. Phys. 1614

[28] Pronschinske A, Chen Y, Lewis G F, Shultz D A, Calzolari A, Nardelli M B and Dougherty D B 2013 Nano Lett. 131429

[29] Guionneau P, Le Gac F, Lakhoufi S, Kaiba A, Chasseau D, Létard J F, Négrier P, Mondieig D, Howard J A K and Léger J M 2007 J. Phys.: Condens. Matter. 19326211

[30] Zoppellaro G, Tucek J, Ugolotti J, Aparicio C, Malina O, Cépe K and Zboril R 2017 Chem. Mater. 298875

[31] Gruber M, Davesne V, Bowen M, Boukari S, Beaurepaire E, Wulfhekel W and Miyamachi T 2014 Phys. Rev. B 89195415

[32] Félix G, Nicolazzi W, Salmon L, Molnár G, Perrier M, Maurin G, Larionova J, Long J, Guari Y and Bousseksou A 2013 Phys. Rev. Lett. 110235701

[33] Raza Y et al 2011 Chem. Commun. 4711501
[34] Zhang X et al 2017 Adv. Mater. 291702257

[35] Zhang X et al 2015 J. Phys. Chem. C 11916293

[36] Palamarciuc T, Oberg J C, El Hallak F, Hirjibehedin C F, Serri M, Heutz S, Létard J F and Rosa P 2012 J. Mater. Chem. 229690

[37] Real J A, Muñoz M C, Faus J and Solans X 1997 Inorg. Chem. 363008

[38] Zhang X, Palamarciuc T, Rosa P, Létard J F, Doudin B, Zhang Z, Wang J and Dowben P A 2012 J. Phys. Chem. C 11623291

[39] Moliner N et al 2002 J. Phys. Chem. B 1064276

[40] Beniwal S et al 2016 J. Phys.: Condens. Matter 28206002

[41] Cullity B D 1956 Elements of X-Ray Diffraction (New York: Addison-Wesley)

[42] Wäckerlin C, Donati F, Singha A, Baltic R, Decurtins S, Liu S X, Rusponi S and Dreiser J 2018 J. Phys. Chem. C 1228202

[43] Pronschinske A, Bruce R C, Lewis G, Chen Y, Calzolari A, Buongiorno-Nardelli M, Shultz D A, You W and Dougherty D B 2013 Chem. Commun. 4910446

[44] Hao G et al 2019 Appl. Phys. Lett. 114032901

[45] Zhang X, Palamarciuc T, Létard J-F, Rosa P, Lozada E V, Torres F, Rosa L G, Doudin B and Dowben P A 2014 Chem. Commun. $\mathbf{5 0} 2255$

[46] Franz R and Wiedemann G 1853 Ann. Phys. Chem. 165497

[47] Larionova J, Salmon L, Guari Y, Tokarev A, Molvinger K, Molnár G and Bousseksou A 2008 Angew. Chem., Int. Ed. 478236 